\title{
A Note on the Effects of Spatial Price Discrimination on Output, Welfare and Location
}

\author{
Chin Wei Yang ${ }^{1}$, Hui Wen Cheng $^{2}$, Shih Shen $\mathrm{Chen}^{3}$ \& Ching Wen $\mathrm{Chi}^{4}$ \\ ${ }^{1}$ Department of Economics, Clarion University, Clarion, PA, USA \\ ${ }^{2}$ Department of International Business, Ming Chuan University, Taipei, Taiwan, Republic of China \\ ${ }^{3}$ Department of International Business and Trade, Shu Te University, Kaohsiung, Taiwan, Republic of China \\ ${ }^{4}$ Department of International Business, Ming Chuan University, Taipei, Taiwan, Republic of China \\ Correspondence: Hui Wen Cheng. Department of International Business, Ming Chuan University, 250, Sec. 5, \\ Chung Shan N. Road, Taipei, Taiwan, Republic of China. Tel: 886-2-2882-4564 ext. 2319. E-mail: \\ hwcheng@mail.mcu.edu.tw
}

Received: November 12, 2013

Accepted: November 23, 2013

Online Published: January 23, 2014

doi:10.5539/ijef.v6n2p1

URL: http://dx.doi.org/10.5539/ijef.v6n2p1

\begin{abstract}
This paper reexamines the well-known results of Hwang and Mai (1990), which employed two linear demand functions of equal quantity intercept to examine total output, welfare and locations of a monopoly firm. By imposing equal slope value to both linear demand functions, this paper finds the output theorem by Robinson is preserved, while the welfare theorem by Schmalensee may or may not hold as welfare position hinges on plant locations in a linear market under the free on board (FOB) pricing.
\end{abstract}

Keywords: spatial model, optimum location, price discrimination, location, monopoly

\section{Introduction}

The concept of spatial price discrimination can be traced back to the work of the price discrimination by Pigou as early as 1920. Ever since the publication of Robinson's work of adjusted concavity (1933), there has been a proliferation of such related models. They include the papers by Leontief (1940), Edwards (1950), Silberberg (1970), Battalio and Ekelund Jr. (1972), Yamey (1974), Finn (1974), Greenhut and Ohta (1976), Smith and Formby (1981), Schmalensee (1981), Formby et al. (1983), Varian (1985), Shih et al. (1988), Ohta (1988), Hausman and Mackie-Mason (1988), Nahata etc. (1990), and Schwartz (1990). More recently, Cowan (2007) illustrated that total welfare with discrimination is lower as compared to uniform pricing strategy if the slop of demand is log concave or the curvature of direct demand is nondecreasing in the price. The proposition makes liner demand a special case of $\log$ concavity or $q^{\prime \prime} / q^{\prime} \leq 1$, where $q$ is quantity demand and $q^{\prime}$ and $q^{\prime \prime}$ are its first and second derivatives. Cowan (2007) also illustrated that welfare can increase with discrimination if demand slope exhibits extreme convexity.

In the spatial context, Greenhut and Ohta (1972) showed that the total output is greater under the spatial price discrimination than that under the FOB mill price policy for a variable radius of a monopolist's market area. Holahan (1975) proved similar results in terms of the welfare. Beckmann (1976) verified that the total output is the same under both price policies for a fixed market radius. Detailed comparisons of the spatial monopolist can be found in Greenhut et al. (1975), Greenhut (1977), Greenhut et al. (1987), and Ohta (1988). Nevertheless, the firm's location of the aforementioned models is predetermined. In a similar vein, the Weberian location model (Weber, 1929) and it applications (Hoover, 1948; Isard, 1956) assume that the competitor's location is given. To relax this assumption, Hotelling's seminal work (1929) indicated the superiority of a median location in the bounded linear market with zero relocation cost. In the content of taxes, Kitahara and Matsumura (2006) proved that both unit taxes and ad valorem taxes do not affect equilibrium locations of firms in the spatial oligopoly models. Casado-Izaga (2010) showed such "neutrality" result will hold in a framework in which firms are free to practice spatial price discrimination. Most recently, Colombo (2010) expands his model to include the possibility of elastic demand functions. In the context of cost minimization principle, the results by Quinn (1943), Alonso (1964), Rydell $(1967,1971)$ and Snyder (1971) again suggested the optimum median solution. Anderson et al. (1992) compared profit and welfare under different spatial pricing policies. Recently, Cheung and Wang (1995) based on 
the Beckmann model (1989) analyzed location decision and spatial price discrimination in the presence of non-uniform demand. Garella (2002) included durable goods into the price discrimination model similar to Hwang and Mai (1990). More recently, Liang et al. (2006) expanded their spatial monopoly to spatial duopoly model. From a different perspective, Yang et al. (2002) derived and solved a computable spatial Cournot model. In their well-known paper, Hwang and Mai (1990) proved that (i) when two demand curves are linear, there is no possibility of an intermediate location; (ii) if both demand curves are linear with the same quantity intercept values, total output under the discriminatory pricing is less than that under mill pricing; and (iii) the welfare level under spatial price discrimination could be greater than that under simple monopoly even if both demand curves are linear. Their results are sharply different from the previous ones (e.g., median position, Robinson output theorem and Schmalensee's welfare conclusion). The purpose of this paper is to show that in the case of two linear demand curves of equal slopes, instead of equal intercept, as is the case of the H-M model, none of the shocking results in the $\mathrm{H}-\mathrm{M}$ model is necessarily preserved.

\section{FOB Mill Price and Spatial Price Discrimination Models}

Given a bounded linear market of length $s$, a spatial monopolist can locate its plant on any point of the line $(0 \leq x \leq$ $s$ ) to serve both markets at end points, i.e., $x=0$ and $x=s$ where $x$ and $s-x$ denote distances of its plant from market 1 and 2 respectively. Hence, two linear demand curves of each market (Hwang \& Mai, 1990, pp. 568) take the following forms:

$$
\begin{gathered}
q_{1}=\alpha-\beta P_{1}=\alpha-\beta\left(m_{1}+r x\right) \\
q_{2}=a-b P_{2}=a-b\left[m_{2}+r(s-x)\right]
\end{gathered}
$$

where $P_{i}, m_{i}$ and $q_{i}$ are the delivered price, mill price, and quantity demanded in market $i(i=1,2) ; r$ is constant transport rate; $\alpha$ and $a$ are quantity intercepts; and $-1 / \beta$ and $-1 / b$ are the slopes of two demand curves. Following Hwang and Mai, a spatial monopolist under FOB mill price policy $(m)$ attempts to maximize his profit $\pi^{s}$ or:

$$
\pi^{s}(m, x)=\{\alpha-\beta(m+r x)+a-b[m+r(s-x)]\}(m-c)
$$

where $c$ is a constant marginal cost and superscripts denotes f.o.b. pricing. The first-order condition and optimum mill price $m^{s}$, quantity in market $1 q_{1}^{s}$, quantity in market $2 q_{2}^{s}$, total quantity $Q^{s}$ and profit can be shown as:

$$
\begin{gathered}
\frac{\partial \pi^{s}}{\partial m}=(\alpha+a)+c(\beta+b)-r[\beta x+b(s-x)]-2(\beta+b) m=0 \\
m^{s}=\frac{(\alpha+a)+c(\beta+b)-r[b s+x(\beta-b)]}{2(\beta+b)} \\
q_{1}^{s}=\frac{(\beta+b)(2 \alpha-\beta c)-\beta(\alpha+a)-\beta r[\beta x-b(s-3 x)]}{2(\beta+b)} \\
q_{2}^{s}=\frac{(\beta+b)(2 a-b c)-b(\alpha+a)-b r[\beta(2 s-3 x)+b(s-x)]}{2(\beta+b)} \\
Q^{s}=q_{1}^{s}+q_{2}^{s}=\frac{(\alpha+a)-c(\beta+b)-r[b s+x(\beta-b)]}{2} \\
\pi^{s}=\frac{\{(\alpha+a)-c(\beta+b)-r[b s+x(\beta-b)]]^{2}}{4(\beta+b)}
\end{gathered}
$$

In contract, a spatial monopolist can charge different mill prices (superscript $d$ ) in order to maximize his total profit $\pi^{d}$ or:

$$
\pi^{d}\left(m_{1}, m_{2}, x\right)=\left[\alpha-\beta\left(m_{1}+r x\right)\right]\left(m_{1}-c\right)+\left\{a-b\left[m_{2}+r(s-x)\right]\right\}\left(m_{2}-c\right)
$$

The first-order condition and the resulting optimum mill prices in market $1 m_{1}^{d}$, mill price in market $2 m_{2}^{d}$, quantity in market $1 q_{1}^{d}$, quantity in market $2 q_{2}^{d}$, total quantity $Q^{d}$ and profit are:

$$
\begin{gathered}
\frac{\partial \pi^{d}}{\partial m_{1}}=\alpha+\beta(c-r x)-2 \beta m_{1} \\
\frac{\partial \pi^{d}}{\partial m_{2}}=a-2 b m_{2}-b r(s-x)+b c=0
\end{gathered}
$$




$$
\begin{gathered}
q_{1}^{d}=\frac{\alpha-\beta(c+r x)}{2} \\
q_{2}^{d}=\frac{a-b[c+r(s-x)]}{2} \\
Q^{d}=q_{1}^{d}+q_{2}^{d}=\frac{(\alpha+a)-c(\beta+b)-r[b s+x(\beta-b)]}{2} \\
\pi^{d}=\frac{[\alpha-\beta(c+r x)]^{2}}{4 \beta}+\frac{\{a-b[c+r(s-x)]\}^{2}}{4 b}
\end{gathered}
$$

The convexity of the profit functions under two pricing systems with respect to location variable $x$ may be established as following:

$$
\begin{aligned}
& \frac{\partial^{2} \pi^{s}}{\partial x^{2}}=\frac{r^{2}(\beta-b)^{2}}{2(\beta+b)}>0 \text { for all } b \neq \beta \\
& \frac{\partial^{2} \pi^{d}}{\partial x^{2}}=\frac{(\beta r)^{2}}{2 \beta}+\frac{(b r)^{2}}{2 b}>0 \text { for all } b \text { and } \beta
\end{aligned}
$$

It is evident from (17) that the profit function under FOB mill price policy is strictly convex with respect to $x$ for $b \neq \beta$. As is readily clear, the second derivative is zero for $b=\beta$. Consequently, further investigation is needed to determine the possible values for $x$. In addition, an examination of (18) indicates that the profit function is indeed strictly convex with respect to $x$ for all $b$ and $\beta$. However, in the case of $b=\beta$, solution of $x$ may not be unique. These properties are summarized in the following propositions.

Proposition 1: In the H-M spatial model under FOB mill price policy with two linear demand functions of an equal slope, the optimum location variable $x$ can assume any value between zero and s, i.e., it need not be a corner solution.

Proof: An examination of (9) in the case of $b=\beta$ reveals immediately that total output and profit remain invariant for any value of $x$. That is, $\beta x-b x$ in the bracket of equations (8) and (9) equals zero regardless of $x$ values. As a result, there exists infinite numbers of solutions for $x$.

\begin{tabular}{|c|c|c|c|c|c|c|c|c|c|c|c|c|}
\hline Solution Model & $q_{1}$ & $Q_{2}$ & $Q$ & $m$ & $m_{l}$ & $m_{2}$ & $P_{1}$ & $P_{2}$ & $x$ & $\pi$ & $c s$ & $w$ \\
\hline $\begin{array}{l}\text { FOB } \\
x=0.793\end{array}$ & 4.479 & 3.771 & 8.25 & 5.125 & & & 5.521 & 5.229 & 0.793 & 34.031 & 17.141 & 51.172 \\
\hline $\begin{array}{l}\text { FOB } \\
x=0.1\end{array}$ & 4.825 & 3.425 & 8.25 & 5.125 & & & 5.175 & 5.575 & 0.1 & 34.031 & 17.506 & 51.537 \\
\hline $\begin{array}{l}\text { FOB } \\
x=0.6\end{array}$ & 4.575 & 3.675 & 8.25 & 5.125 & & & 5.425 & 5.325 & 0.6 & 34.031 & 17.218 & 51.249 \\
\hline $\begin{array}{l}\text { FOB } a=\alpha=10 \\
x=0.793\end{array}$ & 4.229 & 4.521 & 8.75 & 5.375 & & & 5.771 & 5.479 & 0.793 & 38.281 & 19.162 & 57.443 \\
\hline $\begin{array}{l}\text { FOB } a=\alpha=10 \\
x=0\end{array}$ & 4.625 & 4.125 & 8.75 & 5.375 & & & 5.375 & 5.875 & 0 & 38.281 & 19.203 & 57.484 \\
\hline $\begin{array}{l}\text { FOB } a=\alpha=10 \\
x=1\end{array}$ & 4.125 & 4.625 & 8.75 & 5.375 & & & 5.875 & 5.375 & 1 & 38.281 & 19.203 & 57.484 \\
\hline $\begin{array}{l}\operatorname{SPD} a=\alpha=10 \\
x=0\end{array}$ & 4.5 & 4.25 & 8.75 & & 5.5 & 5.25 & 5.5 & 5.75 & 0 & 38.312 & 19.156 & 57.469 \\
\hline $\begin{array}{l}\operatorname{SPD} a=\alpha=10 \\
x=1\end{array}$ & 4.25 & 4.5 & 8.75 & & 5.25 & 5.5 & 5.75 & 5.5 & 1 & 38.312 & 19.156 & 57.469 \\
\hline SPD a $=9 x=0$ & 4.5 & 3.75 & 8.25 & & 5.5 & 4.75 & 5.5 & 5.25 & 0 & 34.312 & 17.156 & 51.469 \\
\hline
\end{tabular}

Note that the quantity intercept need not be the same for the two linear demand functions. We employ the parameters by Hang and Mai (except for $a=9$ and $\alpha=10$ so that $a \neq \alpha$ as a more general case) to verify the validity of proposition 1. As expected, $x$ can assume any value between 0 and 1 (see the first 3 rows in Table 1). The profit (34.031) and total output 8.25 remain in unchanged.

Table 1. Simulations of the H-M spatial monopoly models

*The simulation unless otherwise mentioned is based on following parameters: $\alpha=10, a=9, b=\beta=1, c=1, r=0.5$ and $s=1$. In addition, $c s=$ consumers surplus, $\mathrm{FOB}=\mathrm{FOB}$ mill price policy, $\mathrm{SPD}=$ spatial price discrimination policy. An optimization package of GINO (Liebman et al, 1986) is used in our simulation. 
Proposition 2: In the H-M model under spatial price discrimination policy with two identical linear demand functions of an equal intercept and an equal slope, the optimum location variable can assume either zero or s, i.e., it is a corner solution but not a unique solution.

Proof: An examination of (16) in the case of $a=\alpha$ and $b=\beta$ indicates readily that $\pi^{d}(x=0)=\pi^{d}(x=s)$. Hence, it does not matter whether the plant is located in market 1 or 2 since the profit level remains unchanged in either case.

In light of these results, proposition 1 of the H-M paper may very well not hold in the case of $b=\beta$. The result of proposition 2 is verified in our simulation (2nd and 3nd last row of Table 1).

The Robinson output theorem states that the total output under FOB mill price and spatial price discrimination policies is the same if the demand curves are linear. Hwang and Mai (1990) proved that this property is not preserved in their model. Their proposition 2 states that total output under discriminatory pricing is definitely less than that under FOB pricing for the two linear demand curves having the same quantity intercept (pp. 572). In the case of an equal slope $b=\beta$, their proposition 2 does not hold. It is also true that, Joan Robinson's output theorem prevails as stated in the following proposition:

Proposition 3: In the H-M spatial model with two linear demand functions of an equal slope, total output level under both $F O B$ and discriminatory pricing is identical.

Proof: In the case of $b=\beta$, equation (8) is equivalent to (15) for all admissible value of $x$. As a result:

$$
Q^{s}=Q^{d}=(\alpha+a-\beta r s) / 2-c \beta
$$

The result is verified in Table $1(\mathrm{Q}=8.75$ in the fifth and seventh rows).

Note that the above proof of the Robinson output theorem is valid even in the case of $a \neq \alpha$, i.e., quantity intercept need not be equal. A simulation result based on the parameters from Hwang and Mai (with the quantity intercept of market 2 decreased by one unit or $a=9$ ) can easily verify the statement of proposition $3(\mathrm{Q}=8.25$ in the first 3 rows and the last row of Table 1). Now, we proceed to examine proposition 3 of the H-M model in which it was proved that the welfare level under spatial price discrimination can be greater than that under simple mill price even if both demand curves are linear (Hwang \& Mai, 1990, pp. 573). Proposition 3 of the H-M model hence weakens Schmalensee's conclusion that FOB mill pricing is always preferred in terms of the welfare measure. In the case of $b=\beta$, it can be shown that the welfare level may very well not be unique even for a given set of parameters. This result is established in proposition 4.

Proposition 4: In the H-M spatial model with two linear demand functions of an equal slope, the welfare measure under FOB mill price policy can be less or greater than that under spatial price discrimination policy for a given set of values of parameters.

Proof: The welfare measure $(w)$ under two pricing policies is the sum of consumers' surplus $(c s)$ and producers' profit:

$$
\begin{aligned}
& w^{s}=c s^{s}+\pi^{s}=\frac{1}{2}\left(\frac{q_{1}^{s^{2}}}{\beta}+\frac{q_{2}^{s^{2}}}{b}\right)+\pi^{s} \\
& w^{d}=c s^{d}+\pi^{d}=\frac{1}{2}\left(\frac{q_{1}^{d^{2}}}{\beta}+\frac{q_{2}^{d^{2}}}{b}\right)+\pi^{d}
\end{aligned}
$$

From (9) total profit level under FOB mill price policy is invariant to the optimum values of $x$ as long as $b=\beta$. However, optimum values of $q_{1}{ }^{s}$ and $q_{2}{ }^{s}$ will vary with a change in $x$ as can be readily detected from (6) and (7) despite the fact that the total output level remains invariant with respect to different $x$ values. As a result, there exists infinite number of values for $w^{s}$. On the other hand, $w^{d}$ is unique since $x$ is unique; hence outputs in individual markets and profit level are also unique. In this case, for a given $a, b, \alpha, \beta, r, s$ and $c$, it is quite possible that $w^{s}>w^{d}$ and $w^{s}<w^{d}$ can hold at the same time since there exist infinite choices for $w^{s}$. Some $w^{s}$ may be greater and some may be less than the corresponding $w^{d}$. The size of (19) and (20) cannot be determined within the profit-maximizing framework proposed by Hwang and Mai.

Proposition 4 suggests that the Schmalensee's welfare theorem can be satisfied and violated as long as $b=\beta$. In addition it is found that, the welfare anomaly occurs in the H-M model only in the case of $r>1.749$. In order to verify proposition 4 of this paper, we again use their parameters (except for $b=\beta=1, a=9$ ) and report the results in Table 1. For example, $w^{s}(x=0.1)=51.537$ or the second row exceeds $w^{d}(x=0)=51.469$ or the last row which is in turn greater than $w^{s}(x=0.6)=51.249$ or the third row for $b=\beta=1, \alpha=10, a=9, s=1, c=1$, and $r=0.5$. In addition, proposition 4 holds as well if we let quantity intercept be of the same value ( $a=\alpha=10$ or identical demand curve), 
57.443 (4th row or FOB with $x=0.793$ ) $<57.469$ (8th row or SPD with $x=1$ ) $<57.484$ (6th row or FOB with $x=1$ ). In view of the result, it is difficult to support or refute Schrnalensee's welfare theorem even for a single value of $r$ without having more assumptions or information imposed to the model.

\section{Conclusion}

In this note, we investigate the neglected case of the H-M model (equal quantity intercept but different slopes) with two linear demand functions of an equal slope but different intercepts. Within this framework, the optimum plant location can be anywhere within the line market for a profit-maximizing spatial monopolist who practices FOB mill price policy. This is in direct contradiction to the corner solution derived by Hwang and Mai. In the case of spatial price discrimination, we have proven that the optimum plant location with two identical demand functions can be either $x=0$ or $x=s$, that is, a corner but non-unique solution. As for total output level of a spatial monopolist, Robinson's output theorem is preserved for any two well-behaved linear demand functions of an equal slope. Again, this contradicts the proposition of the H-M model in which total output under FOB pricing exceeds total output under spatial price discrimination policy. Lastly, we also have shown that Schmalensee's welfare theorem can be refuted or supported even for a single value of $r$. More assumptions or information is required to determine the welfare position. In summary, our case of $b=\beta$ is shown to be at odds with many striking results correctly proved by Hwang and Mai. This is to say some of the classical results may very well be preserved.

\section{References}

Alonso, W. (1964). Location theory. In J. Friedmann \& W. Alonso (Eds.), Regional development and planning (pp. 78-106). Cambridge, MA: M. I. T. Press.

Anderson, S. P., Palma, A. D., \& Thisse, J. F. (1992). Social surplus and profitability under different spatial pricing policies. Southern Economic Journal, 58, 934-949. http://dx.doi.org/10.2307/1060230

Battalio, R. C., \& Ekelund, R. B. Jr. (1972). Output change under third-degree price discrimination. Southern Economic Journal, 39, 285-290. http://dx.doi.org/10.2307/1056599

Beckmann, M. J. (1976). Spatial price policies revisited. Bell Journal of Economics, 7, 619-630. http://dx.doi.org/10.2307/3003275

Casado, I. F. J. (2010). Tax effects in a model of spatial price discrimination: A note. Journal of Economics, 99, 277-282. http://dx.doi.org/10.1007/s00712-010-0109-4

Cheung, F. K., \& Wang, X. (1995). Spatial price discrimination and location choice with non-uniform demands. Regional Science and Urban Economics, 25, 59-73. http://dx.doi.org/10.1016/0166-0462(94)02076-S

Colombo, S. (2010). Tax effects on equilibrium locations. Journal of Economics, 101, 267-275. http://dx.doi.org/10.1007/s00712-010-0152-1

Edwards, E. O. (1950). The analysis of output under discrimination. Econometrica, 18, 163-172. http://dx.doi.org/10.2307/1907267

Finn, T. J. (1974). The quantity of output in simple monopoly and discriminating monopoly. Southern Economic Journal, 41, 239-243. http://dx.doi.org/10.2307/1056735

Formby, J. P., Layson, S. K., \& Smith, W. J. (1983). Price discrimination, 'adjusted concavity', and output changes under conditions of constant elasticity. Economic Journal, 93, 892-899. http://dx.doi.org/10.2307/2232754

Garella, P. G. (2002). Price discrimination and the location choice of a durable goods monopoly. Regional Science and Urban Economics, 32, 765-773. http://dx.doi.org/10.1016/S0166-0462(01)00102-8

Greenhut, J. G. (1977). On the economic advantages of spatially discriminatory prices compared with F. O. B. prices. Southern Economic Journal, 44, 161-166. http://dx.doi.org/10.2307/1057311

Greenhut, M. L., \& Ohta, H. (1972). Monopoly output under alternative spatial pricing techniques. American Economic Review, 62, 705-713.

Greenhut, M. L., \& Ohta, H. (1976). Joan Robinson's criterion for deciding whether market discrimination reduces output. Economic Journal, 86, 96-103. http://dx.doi.org/10.2307/2230954

Greenhut, M. L., Hwang, M., \& Ohta, H. (1975). Observations on the shape and relevance of the spatial demand function. Econometrica, 43, 669-682. http://dx.doi.org/10.2307/1913076

Greenhut, M. L., Norman, G., \& Hung, C. S. (1987). The economics of imperfect competition: A spatial approach. Cambridge, MA: Cambridge University Press. 
Hausman, J. A., \& Mackie, M. J. K. (1988). Price discrimination and patent policy. Rand Journal of Economics, 19, 253-265. http://dx.doi.org/10.2307/2555703

Holahan, W. L. (1975). The welfare effects of spatial price discrimination. The American Economic Review, 65, 498-503.

Hoover, E. M. (1948). The location of economic activity. New York, NY: McGraw-Hill.

Hotelling, H. (1929). Stability in competition. Economic Journal, 39, 41-57. http://dx.doi.org/10.2307/2224214

Hwang, H., \& Mai, C. C. (1990). Effects of spatial price discrimination on output, welfare, and location. American Economic Review, 80, 567-575.

Isard, W. (1956). Location and Space Economy. Cambridge, MA: M.I.T. Press.

Kitahara, M., \& Matsumura, T. (2006). Tax effects in a model of product differentiation: A note. Journal of Economics, 89, 75-82. http://dx.doi.org/10.1007/s00712-006-0180-z

Leontief, W. W. (1940). The theory of limited and unlimited discrimination. Quarterly Journal of Economies, 54, 490-501. http://dx.doi.org/10.2307/1882453

Liang, W. J., Hwang, H., \& Mai, C. C. (2006). Spatial discrimination: Bertrand vs. cournot with asymmetric demands. Regional Science and Urban Economics, 36, 790-802. http://dx.doi.org/10.1016/j.regsciurbeco.2006.04.001

Liebman, J., Lasdon, L., Schrage, L., \& Waren, A. (1986). Modeling and optimization with GINO. Palo Alto, CA: The Scientific Press.

Nahata, B., Ostaszewski, K., \& Sahoo, P. K. (1990). Direction of price changes in third-degree price discrimination. American Economic Review, 80, 1254-1258.

Ohta, H. (1988). Spatial price theory of imperfect competition. College Station, TX: Texas A\&M University Press.

Pigou, A. C. (1920). The economics of welfare. London, UK: Macmillan and Company.

Quinn, T. A. (1943). The hypothesis of median location. American Sociological Review, 8, 148-156. http://dx.doi.org/10.2307/2085879

Robinson, J. (1933). The economics of imperfect competition. London, UK: Macmillan.

Rydell, C. P. (1967). A note on a location principle: Between the median and the mode. Journal of Regional Science, 7, 185-192. http://dx.doi.org/10.1111/j.1467-9787.1967.tb01435.x

Rydell, C. P. (1971). A note on the principle of median location: Comment. Journal of Regional Science, 11, 395 396. http://dx.doi.org/10.1111/j.1467-9787.1971.tb00271.x

Schmalensee, R. (1981). Output and welfare implications of monopolistic third-degree price discrimination. American Economic Review, 71, 242-247.

Schwartz, M. (1990). Third-degree price discrimination and output: Generalizing a welfare result. American Economic Review, 80, 1259-1262.

Shih, J. J., Mai, C. C., \& Liu, J. C. (1988). A general analysis of the output effect under third-degree price discrimination. Economic Journal, 98, 149-158. http://dx.doi.org/10.2307/2233516

Silberberg, E. (1970). Output under discriminatory monopoly. Southern Economic Journal, 37, 84-87. http://dx.doi.org/10.2307/1056682

Smith, W. J., \& Formby, J. P. (1981). Output changes under third-degree price discrimination: A reexamination. Southern Economic Journal, 48, 164-171. http://dx.doi.org/10.2307/1058608

Snyder, R. (1971). A note on the principle of median location. Journal of Regional Science, 11, 391-393. http://dx.doi.org/10.1111/j.1467-9787.1971.tb00270.x

Varian, H. R. (1985). Price discrimination and social welfare. American Economic Review, 75, 870-875.

Weber, A. (1929). Alfred Weber's theory of the location of industries. Chicago, IL: The University of Chicago Press.

Yang, C. W., Hwang, M. J., \& Sohng, S. N. (2002). The cournot competition in the spatial equilibrium model. Energy Economics, 24, 139-154. http://dx.doi.org/10.1016/S0140-9883(01)00094-9

Yarney, B. S. (1974). Monopolistic price discrimination and economic welfare. Journal of Law and Economics, 17, 377-380. http://dx.doi.org/10.1086/466797 


\section{Copyrights}

Copyright for this article is retained by the author(s), with first publication rights granted to the journal.

This is an open-access article distributed under the terms and conditions of the Creative Commons Attribution license (http://creativecommons.org/licenses/by/3.0/). 